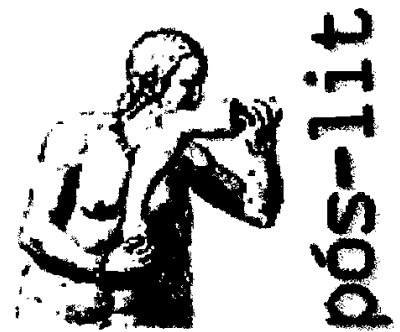

Programa de Pós-Graduação em

\section{Letras: Estudos Literários} da Faculdade de Letras da UFMG

Artigo disponível em http://www.letras.ufmg.br/poslit

\section{ENTRE 0 INSTANTE E 0 TEMPO: UM POEMA DE CASSIANO RICARDO}

José Américo Miranda UFMG

\section{ABSTRACT}

The poem "Serenata sintética" by Cassiano Ricardo is analysed in its phonological aspects and in its imagery. The possibilities of narrative development in the scope of brief lyric forms as well as through the ideogramic method are investigated as mechanisms through which sense is introduced in the structure of the text. 
Na literatura, arte do tempo, a obra tende, ao final de seu processo constitutivo, a configurar-se como imagem, onde tudo é simultaneidade. A obra de arte literária, se algum recurso possui para insurgir-se contra 0 tempo, para imobilizá-lo, como o faz uma fotografia, esse recurso é o da repetição. $\mathrm{O}$ território em que a arte literária mais o utiliza é aquele em que o estrato fônico, elemento puramente temporal da forma, trabalha contra o tempo: o verso, a poesia, particularmente no gênero lírico.

A propósito da alta incidência de repetições na poesia lírica, Affonso Romano de Sant'Anna, em seu livro dedicado à obra de Carlos Drummond de Andrade, observou:

Parece haver uma relação entre a repetição e o que seja lirismo em poesia. Ou melhor: a repetição é um atributo mais encontradiço na poesia lírica do que na dramática ou na épica, pois estas são narrativas em desenvolvimento e em tal processo a linguagem raramente se volta sobre si mesma retardando o avanço do enredo. Já na poesia lírica a repetição chega a se constituir em elemento estrutural da composição.

Destinado à fixação da experiência do instante, o gênero lírico utiliza preferencialmente, como observa Emil Staiger ${ }^{2}$, as formas breves. A repetição, destinada a intensificar e conferir nitidez à imagem, é, ainda na expressão de Affonso Romano de Sant'Anna, "uma forma de abolir o tempo". Surpreende, pois, que sua utilização intensiva no interior de formas breves não tenha sido ainda associada a esta outra forma de fixar o instante: a fotografia.

Por sua tendência para afirmar-se contra o tempo, que o aproxima da fotografia, o poema lírico torna-se o lugar privilegiado de aplicação do princípio ideogrâmico. Por meio dele, uma língua como a nossa, linear e analítica, insurge-se contra sua própria natureza, passando a aspirar à simultaneidade da apreensão instantânea.

$\mathrm{Na}$ poesia brasileira, como se sabe, essa prática chegou à poesia concreta através da aplicação que encontrara na obra de Ezra Pound, que a recebera, por sua vez, do trabalho de Ernest Fenollosa sobre os caracteres da escrita chinesa como instrumento para a poesia ${ }^{3}$ e do estudo direto das línguas orientais. Antes, porém, que a poesia concreta assumisse essas proposiçóes e as transformasse em programa de trabalho, o método

\section{SANT'ANNA, 1972. p. 16. \\ 2. CF. STAIGER, 1975. p. 19.75}

3. 0 ensaio de Fenollosa pode ser encontrodo em CAMP0S, 1977. p. 115-162. ideogrâmico já produzira, na obra de Cassiano Ricardo, um pequeno grande poema:

\section{Serenata sintética}

Rua

torta.

Lua

morta.

Tua

porta. ${ }^{4}$

Chamado, por Nelly Novaes Coelho, de "concretista avant la

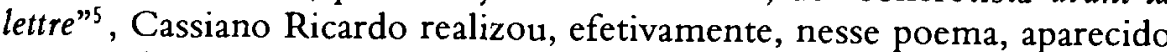
em Um dia depois do outro (1947), algo caro à poesia concreta: um máximo de síntese, despojamento discursivo quase absoluto. A intenção de síntese encontra-se não só implícita na forma que assumiu o poema, mas foi anunciada em seu próprio título, que, em termos de extensão, quase 0 alcança.

Há, entretanto, algo que o distingue da poesia concreta: enquanto esta abolia a distinção entre formas primária e secundária (ou entre os planos do significante e do significado), reduzindo ambas ao denominador comum da estrutura, o poema de Cassiano Ricardo aplica o método ideogrâmico ao nível da imagem, que se distingue claramente do enunciado verbal (forma primária) que o instaura. Nesse poema, as palavras, como material significante, distinguem-se ainda das imagens que evocam, embora se conjuguem com elas de modo muito íntimo, para a realização de um efeito total.

As imagens evocadas pelas palavras, assim como elas próprias, articulam-se não de acordo com a sintaxe da língua, mas segundo a parataxe própria da montagem cinematográfica e do ideograma. A serenata apresenta-se-nos como o produto da apreensão simultânea da paisagem urbana (rua), da situação temporal (noite) e da localização da persona do poeta (diante da porta).

4. RICARD0, 1957. p. 279. Existem diversos versōes deste poema; em muitas, a disposiçōo das versos na pógino, ossim cama su sequêencia, nõo é a mesma que utilizamos oqui. Embora os varioģñes sejom relevantes para o sentido, optamos pela enfoque de openas unio delos, a que se encontra no ediç̄o citoda dos Poesios completers.

5. COELHO, 1972. p. 60 . 
Composto por três dísticos, com rimas consoantes e alternadas, o poema situa-se nos confins mínimos do verso e máximos da condensação de linguagem. Três substantivos concretos, dois adjetivos, um pronome: e eis que imagens impregnadas de sentido por todo um complexo históricosócio-cultural, herança coletiva de um povo, e emocional, dado da memória individual do poeta, apresentam-se ao leitor.

O verso utilizado, monossilábico, conforme a técnica de decomposição do verso mais utilizada em língua portuguesa, é bastante raro; costuma ser interpretado como exercício de virtuosismo e mestria formal; alguns tratados de versificação praticamente o ignoram. Se levarmos em consideração as sílabas átonas finais, cada verso assume a conformação de um pé troqueu, unidade rítmica em que um primeiro tempo forte é seguido por um fraco. Trata-se de um ritmo de andamento célere (do grego "trochaios", rápido), sem dúvida relevante para o sentido, adequado à rapidez com que as imagens acorrem a nossas mentes.

O timbre das vogais tônicas, u e o (aberto) alternados, ambas de articulação posterior, lança sobre o quadro das imagens visuais um colorido melancólico e soturno, que confere ao poema um tom elegíaco, diríamos mesmo de luto. O sentido do poema começa a configurar-se aí, no estrato fônico, que constrói para nós, em três golpes, a totalidade da imagem.

A seqüência sonora, linha melódica dos três dísticos, é quase integralmente repetida três vezes. Apenas os fonemas iniciais de cada verso variam, mas, mesmo eles, apresentam qualidades sonoras distintivas que muito os aproximam. Os fonemas dos primeiros versos dos dois primeiros dísticos são líquidas sonoras ( $\mathrm{r}$ e l). Durante sua emissão o canal fonatório permanece metade aberto, metade fechado. No caso do r, essas metades distribuem-se no tempo: durante metade do tempo da fonação, as vibrações mantêm aberto o canal, durante a outra metade, fechado. No caso do l, as metades são espaciais: durante a fonação o canal permanece fechado em sua porção anterior, mas abre-se entre as bordas laterais da língua e as arcadas dentárias. Esses fonemas líquidos sucessivos convergem, no primeiro verso do último dístico, para o som consonantal $t$, oclusivo, alveolar e surdo:

\section{$\mathrm{R}$ ua \\ L ua \\ T ua}

Como o caráter do fechamento dos fonemas l e r, o poema hesita entre o espaço e o tempo; entre o registro lírico, retrato instantâneo de uma cena, e o caráter narrativo da seqüência de representações (poderíamos compará-las a fotogramas) que se modificam pouco a pouco, perfazendo a totalidade de uma ação.

A segunda série de fonemas iniciais, os que começam o segundo verso de cada dístico, é toda composta por oclusivos: o primeiro, t, surdo e alveolar; o segundo, $\mathrm{m}$, sonoro, nasal e labial; e o último, $\mathrm{p}$, surdo e labial:

\section{t orta \\ $m$ orta \\ $\mathrm{p}$ orta}

Repare-se, no caso do último fonema, na oclusão do canal fonatório em seu extremo anterior, fechamento máximo possível. Insistimos nessas qualidades porque, como veremos, elas importam para a configuração final do sentido do poema. Quanto aos demais fonemas, todos repetem-se nos três dísticos:

$\mathrm{R}$ ua

$\mathrm{t}$ orta.

L ua

m orta.

T ua

$\mathrm{p}$ orta.

Dos 24 pontos fonológicos constitutivos do poema, não menos que 18 ( 75 por cento) estão comprometidos em repetiçōes ternárias; um índice muito alto, para poema tão breve. A repetição contribui, sem dúvida, para a impressão de simultaneidade, para a ligeireza com que é pintado o quadro apresentado no poema.

No plano das imagens, vamos considerá-lo, inicialmente, pelo alto índice de repetiçōes que apresenta, como um todo instantâneo: rua, lua no céu, casa da mulher amada - realidades que coexistem e se distribuem no espaço. Assim considerado, o poema comporta dois elementos que Roland Barthes assinalou em fotografias: o primeiro é expressão da cultura, é inevitavelmente encontrado, seu código é conhecido, por meio dele a intenção do criador/poeta/fotógrafo pode ser identificada (Barthes o chama de studium); o segundo é algo distinto, que nem sempre pode ser 
encontrado, que rasga o pano de fundo do primeiro e vem atingir o espectador, sem que os códigos culturais o expliquem e traduzam; trata-se da singularidade (Barthes o chama de punctum) ${ }^{6}$. Em "Serenata sintética", o studium encontra-se na serenata (código cultural); o punctum consiste na singularidade desta serenata; o studium, no que, nas serenatas em geral, pode ser reduzido a um quadro estático; o punctum, na narrativa que se inscreve no cenário descrito; o studium é instantaneamente reconhecido por todos; o punctum irrompe do poema de maneira imprevista, não codificado de maneira usual.

Examinaremos, em primeiro lugar, os dados de ordem cultural, os códigos dominados pela coletividade, contidos no poema e anunciados em seu título pela palavra "serenata". "Rua/torta", realidade mencionada no primeiro dístico, encontra-se já em nosso espírito, como que prefigurada, anunciada pelo título do poema; sua menção vem apenas tornála nítida e concreta, conforme a expectativa. Ela é um saber prévio do leitor, que conhece a realidade de não se fazerem serenatas em grandes cidades, ao lado de grandes vias com tráfego intenso, ou ao pé de edifícios de muitos andares. As serenatas são práticas próprias das pequenas cidades, são hábito antigo, tradicional, anterior à existência da luz elétrica e do automóvel. Nessas cidades o desenho das ruas é determinado pelo relevo do solo, sinal de um tempo em que o homem ainda não dispunha de meios técnicos para impor à natureza as linhas retas ditadas pela razão. Típicas dos séculos passados, essas cidades conservaram-se intactas, na maioria dos casos, pela pobreza que impossibilitou a renovação de sua arquitetura e urbanismo. O caso exemplar é a cidade dos tempos coloniais.

"Lua/morta", tanto quanto o primeiro dístico, vem apenas confirmar a expectativa do leitor, que conhece a serenata como prática própria das noites de luar. O dístico, entretanto, introduz algo novo, inesperado, o adjetivo "morta" qualificando "lua". O tom enlutado do poema, que atribuímos, nas observações sobre seu estrato fônico, à articulação posterior de todas as suas vogais tônicas, começa a ser preenchido semanticamente na forma secundária do poema (ao nível da significação). A "morte" associada à lua pode ser interpretada de várias maneiras. Nelly Novaes Coelho, na obra já citada, concordando com o autor do poema ${ }^{7}$, entendeu-a como lua já posta, ou em vias de se pôr, como sinal de madrugada, situação temporal da serenata. Essa é, sem dúvida, uma leitura apropriada, que leva em conta a forma secundária do poema em sua relação com a realidade; ela o interpreta à luz dos dados culturais implicados pela palavra "serenata".

Outras leituras, porém, podem ser feitas, sem que se negue a anterior. Se considerarmos o poema em suas relações com a série literária a que pertence, a da poesia lírica, a "lua" pode ser considerada um dos elos entre o poema e a série, e um elo especial, já que, por meio do adjetivo "morta", o poema novo introduz modificações nas conotações míticas de que a lua se revestia na poesia do passado. É bastante conhecido o esforço dos poetas modernos para desmitificá-la. Manuel Bandeira, num poema ("Satélite"), escreveu:

Ah Lua deste fim de tarde,

Demissionária de atribuições românticas,

Sem show para as disponibilidades sentimentais!

Fatigado de mais-valia,

Gosto de ti assim:

Coisa em si,

- Satélite.

Carlos Drummond de Andrade, por sua vez, em "Casamento do céu e do inferno", referiu-se a ela nos seguintes termos:

No azul do céu de metileno

A lua irônica

diurética

é uma gravura de sala de jantar.'

Nas condições de trompe l'oeil, gravura kitsch de uma sala de jantar, e de coisa em si, satélite, a lua perde sua dimensão mítica. Por isso ela poderia estar "morta", morta como fonte de inspiração para poetas.

Um outro fator, extraliterário, que poderia ter contribuído para sua morte enquanto mito, é o início da corrida espacial e da disputa pela conquista da lua entre americanos e russos, nos tempos da guerra fria. Esse fator não pode ser desprezado, se considerarmos a data de publicação do poema (Um dia depois do outro, 1947) e o interesse que seu autor, nas décadas subseqüentes, dedicaria às viagens espaciais. Outros poetas cantaram a "morte" da lua, associando-a à corrida espacial, que significaria

8. BANDEIRA, 1970. p. 232

9. ANDRADE, 1967, p. 54. 
o fim do "romantismo" das noites de seresta. Numa canção que fez muito sucesso, intitulada "Lunik 9", Gilberto Gil, entre nostálgico e irônico, diria:

Poetas seresteiros namorados
Correi
É chegada a hora de escrever e cantar
Talvez as derradeiras
Noites de luar
(...)
A lua foi alcançada
Afinal, muito bem
Confesso estou contente também!
A mim me resta nisso
Tudo uma tristeza só
Talvez não tenha mais luar pra clarear
Minha canção
O que será do verso sem luar?
O que será do mar, da flor, do violão?
Tenho pensado tanto mas nem sei..."

Portanto, morta poderia estar também a serenata, ao tempo em que poema foi composto; não só porque o país se urbanizara, mas também porque o luar já se encontrava ameaçado em sua dimensão mítica. Não faltam, pois, razões para justificar a "morte" da "lua"; todas elas, entretanto, são exteriores ao poema.

Cassiano Ricardo, contudo, foi dos mais ardorosos defensores da autonomia do poema, de sua auto-suficiência como objeto, de sua compreensão como

objeto de palavras que obedece a um sistema peculiar, com soluções de linguagem que só ele realiza, com recursos compositivos que a tecnologia, a cibernética, os 'mass media' lhe suscitam, com as suas 'montagens', seu apelo às 'metáforas radicais'; com a incorporação do espaço da página à sua estrutura (dialética do espaço em branco com o em preto); com a inclusão, no verbal, do não-verbal; com ingredientes plásticos e visuais que o 'diversificam' , 'desprosificam' e lhe dão fisionomia autônoma entre as demais criaçōes artísticas e literárias."

Diante desses argumentos, que nortearam grande parte da produção poética do autor, e considerando que "Serenata sintética" situase na raiz mesma dessas questões, as razões assinaladas para a "morte" da

\section{GLL, 1975. Disco long Play, álbum duplo.}

11. RICARDO, Cossiono. Autonomismo. In: BRAYNER, 1979. p. 43. "lua" parecem-nos insuficientes; há ainda uma outra, interna e inerente à estrutura do poema. Ela relaciona-se com o que o poema traz de singular, com seu punctum, com a experiência que ele narra, que nos atinge em meio aos elementos culturalmente codificados.

Antes, porém, de abordarmos esse ponto, passemos ao último dístico do poema. "Tua/porta" traz-nos outra surpresa. Embora a palavra "porta" venha emparelhar-se com as rimas dos dois dísticos anteriores, satisfazendo uma expectativa auditiva, sua presença, no poema, surpreende, já que o lugar diante do qual se faz a serenata é, tradicionalmente, a janela. Pode-se pensar que em muitas casas há portas contíguas a janelas, e que o procedimento retórico da metonímia justifique a tomada de uma pela outra. Há que objetar-se, entretanto, que tais janelas são as da sala, não as da alcova. Fosse a rima a justificativa única para a presença da palavra "porta" no poema, concluiríamos, lembràndo Drummond, que o poeta teria encontrado a rima, sem encontrar a soluçāo. Não obstante, o poema é melhor do que poderíamos imaginar. A porta também se explica.

Por meio da justaposição de três imagens, método ideogrâmico, o poema apresenta-nos, de modo estilizado, como numa pintura ou fotografia, a cena anunciada em seu título. Ele conforma-se, em grande parte, ao código convencional de uma prática cultural popular, mas apresenta uma dissonância, seu punctum: falta-lhe o tom de júbilo inaugural próprio de um amor que se inicia (e se anuncia). Pois a serenata, excetuados os casos em que é feita para relembrar, para nostalgicamente reviver outros tempos, é prática própria da juventude; não só da juventude do seresteiro, mas da juventude, da infância mesma, do próprio amor. Ela é um procedimento de corte amorosa, um galanteio que o amante dirige à mulher pretendida; portanto, freqüentemente, àquela de cujo amor ainda não tem certeza. O gesto de assentimento da bela, nessa espécie de sobrevivência romântica dos códigos do amor cortês, consiste em abrir discretamente, entreabrir, apenas para que passem a luz e o som, um para fora, outro para dentro, uma de suas janelas.

As perguntas que nos surgem, que nos incomodam e perseguem, são estas: de onde vem o tom soturno, elegíaco, o lamento que perpassa o poema? o que é narrado por ele? A melancolia talvez se explique pelo fato de o poeta já contar 52 anos de idade quando compôs o poema. Tal explicação, entretanto, como as outras, que associamos ao studium, seria exterior ao poema. É nele mesmo, naquilo que ele narra, que vamos encontrar o inesperado, é dele que vem a dor pungente que nos atinge. $E$ em sua estrutura que devemos procurar o porquê daquela "lua/morta" e 
daquela "porta".

Temos considerado que a brevidade do poema nos apresenta um "quadro" estático, para o qual contribui o alto índice de redundância introduzido pela repetição, sem alterações, de 18 dos 24 pontos fonológicos que o compõem. Como vimos, apenas as consoantes iniciais de cada verso se alteram no decorrer do poema. Se há algo de novo, uma experiência particular, se há uma dor íntima, que vincularia fortemente o poema à tradição de um lirismo romântico, esse algo só pode surgir desses elementos que introduzem uma dissonância no quadro padrão, socialmente codificado, da serenata. Não nos esqueçamos daquele "tua" no terceiro dístico, que compromete diretamente o "eu" que fala no poema. Tudo isso nos instiga à investigação, a não nos contentarmos com uma leitura que nos revele apenas o óbvio, o studium, que forma o pano de fundo, o cenário, sobre o qual se inscreve a narrativa.

No brevíssimo poema de Cassiano Ricardo, como vimos, a cada novo verso algo se altera: a consoante inicial. Portanto, se algo é aí narrado, só o pode ser pela informação trazida por essas transformações, que podem ser comparadas às pequenas alteraçōes nos fotogramas sucessivos de um filme. São elas, as discretas alteraçōes, que permitem a reconstituição do movimento e instauram o regime temporal da narrativa por imagens. Hesitando entre a apreensāo simultânea da totalidade e a possibilidade de, ainda assim, desenvolver uma narrativa, o poema parece hesitar entre o instante e o tempo.

As consoantes iniciais dos primeiros versos de cada dístico, como vimos, evoluem de líquidas a oclusiva $(r, l, t)$, e as iniciais dos últimos versos são todas oclusivas $(t, m, p)$, alcançando uma oclusão máxima ao fim da seqüência. A presença de oclusivas anteriores ( $t$ e $p$ ), reforçando-se mutuamente, no último dístico, e a referência à amada (tua) justaposta ao substantivo concreto (porta), agora no segundo verso, ao contrário do que sucedera nos versos anteriores, em que os substantivos vinham nos primeiros versos e eram atenuados por adjetivos nos versos seguintes, conduzem-nos à conclusão de que o poeta se deparou com algo sólido à sua frente. Não só a porta se encontrava fechada, mas também o coração pretendido.

Acrescente-se a essas observações o fato de que os três substantivos concretos que formam os núcleos das imagens que compōem ideogramicamente o panorama imagético do poema (rua, lua, porta) variam de uma dimensão cósmica a uma dimensão compatível com a estatura física do homem. Enfim, a janela não se abriu, o "poeta", como se diz popularmente, deu com a cara na porta. Ao homem pequeno coube uma dor grande.

O poema não relata, pois, como quer Nelly Novaes Coelho, "um encontro de amor"|2, ou seu próprio autor, "um idílio"’’. A hesitaçào entre fechamento e abertura, expressa no caráter ambíguo das consoantes líquidas, $\mathrm{r}$ e l, que iniciam o primeiro e o terceiro versos, respectivamente, encontra sua solução no fechamento total da oclusiva t. Essa tendência já se encontrava anunciada nas oclusivas $\mathrm{t}$ e $\mathrm{m}$ dos segundo e quarto versos. A dúvida de quem temia ouvir um "não" encontrou expressão nessas escolhas. Nos versos pares, o percurso fez-se no sentido da oclusiva posterior para as anteriores, culminando a série em p. A hesitação, pois, justificava-se; e mais, indica que o poeta, intuitivamente, já recebera sinais do "não". A negativa total e final, janelas, porta e coração fechados, não foram surpresa completa: há, na estrutura do poema, indícios de que eram previsíveis.

Daí o tom de doloroso lamento, daí a qualidade de "morta" aplicada à lua daquela noite. Daí a presença, ao final do poema e da jornada, do substantivo concreto com que o poeta se depara: a "porta", evidentemente, fechada. ${ }^{14}$

\section{REFERENAIAS BIBLIOGRÁFICAS}

ANDRADE, Corlos Drummond de. Obro completa. Rio de Janeiro: José Aguilar, 1967. BANDERRA, Monuel. Estrela da vida inteiro. Rio de Joneiro: Jesé Oiłmpio, 1970. BARTHES, Rolond. A camaro clara. Lisboo: Ediçoes 70, 1981 BRAYNER, Sônia (Org.). Cosssiono Ricardo. Rio de Janeiro: Civilização Brosileiro, 1979 CAMPOS, Horoldo de (Org). Ideogramo: lógica, poesio, linguagem. São Poulo: Cultrix, 1977 COELHO, Nelly Novaes Orn Cassiano Ricardo: seleta em prosa e verso Rio de Joneiro: Losé Olympio, 1972. GIL, Gilberto. A arte de Giberto Gil. Rio de Janeiro: Phonogrom, 1975. Disco Long Ploy, ólbum duplo. RICARDO, Cassiono. Poesias completas. Rio de Janeiro: José Olympio, 1957 . Algumas reffexōes sobre poética de vanguarda. Rio de Joneiro: José Olympio, 1964. SANT'ANNA, Aflonso Romano de. OHummond, o gauche na tempo. Rio de Janeiri: Lio, 1972. STAIGER, Emil. Conceitos fundamentais do poético. Rio de Joneiro: Tempo Brosileiro, 1975.

2. COELHO, op. cit. p. 61 .

13. RICARBO, 1964. p. 35 .

14. Cobe observor, a tifulo de esclorecimento, que em sua primeira versōo, "A inútil serenoto", (reproduzida no págino seguinte), publicada no livro Um dia depois do outro, de 1947, o poema nao e too sintetico como o que onolisamas.

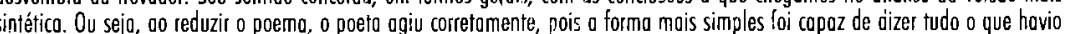
pora ser dito. Devo a lembronça desso primeira versõo do poemo oo Prof. Antônio Corlos Secchin, a quern ogrodeço. 


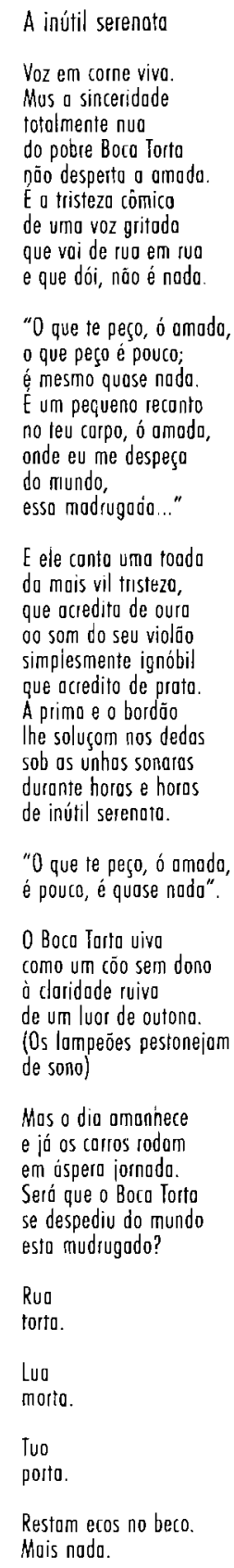

Programa de Pós-Graduação em Letras: Estudos Literários da Faculdade de Letras da UFMG

Artigo disponível em http://www.letras.ufmg.br/poslit 